\title{
A reference to assess cilium phenotype in ciliopathy patients
}

\author{
M Oud $^{1,2^{*}}$, H Arts $^{1,2,3,4}$, R Roepman ${ }^{1,2}$ \\ From Cilia 2014 - Second International Conference \\ Paris, France. 18-21 November 2014
}

\section{Objective}

The cilium presence and constitution of human fibroblasts are accessible and measurable cellular markers for ciliary homeostasis. Fibroblasts are most commonly generated from skin biopsies and comparison of the ciliary phenotype of patients vs controls can be used to identify or evaluate a potential ciliary defect. Subtle differences are difficult to detect, but critical to establish a genotype-phenotype correlation. The aim of this study is to establish the parameters to detect subtle differences in cilium phenotype, and develop a reference for cilium phenotype that can be used to improve diagnosis and prognosis of ciliopathies.

\section{Methods}

We derived fibroblast cell lines from skin biopsies from ciliopathy patients and healthy controls. Ciliogenesis was induced by adding culture medium containing $0.2 \%$ FCS prior to immunocytochemistry. The cells were stained with antibodies against different ciliary proteins to study cilium presence, length, morphology, and intraflagellar transport proteins.

\section{Results}

Fibroblasts from three controls and five patients with different ciliopathies were studied so far. We found major and subtle differences in cilium frequency and phenotype in patients and subtle differences in controls, partly influenced by the culturing conditions. This suggests that there is a significant natural and experimental variation that needs to be taken into account when evaluating the statistical relevance of such findings.

${ }^{1}$ Radboud Institute for Molecular Life Sciences Radboud University Medical Centre, Nijmegen, The Netherlands

Full list of author information is available at the end of the article

\section{Conclusion}

We detected major and subtle differences in cilium phenotype between patients. In addition, we found a natural variation in the cilium phenotype of control fibroblasts. By including more samples, we intend to improve and expand this reference for ciliopathy-associated cilium phenotypes.

\section{Authors' details}

${ }^{1}$ Radboud Institute for Molecular Life Sciences Radboud University Medical Centre, Nijmegen, The Netherlands. '2Department of Human Genetics, Radboud University Medical Centre, Nijmegen, The Netherlands. ${ }^{3}$ Robarts Research Institute, University of Western Ontario, London, Ontario, Canada. ${ }^{4}$ Department of Biochemistry, University of Western Ontario, London, Ontario, Canada.

Published: 13 July 2015

doi:10.1186/2046-2530-4-S1-P60

Cite this article as: Oud et al:: A reference to assess cilium phenotype in ciliopathy patients. Cilia 2015 4(Suppl 1):P60.

\section{() Biolmed Central}

Submit your next manuscript to BioMed Central and take full advantage of:

- Convenient online submission

- Thorough peer review

- No space constraints or color figure charges

- Immediate publication on acceptance

- Inclusion in PubMed, CAS, Scopus and Google Scholar

- Research which is freely available for redistribution 